\title{
Проект 5-100: \\ взгляд через призму теории институциональной коррупции
}

\author{
Е.И. ТРУБНИКОВА*
}

\begin{abstract}
*Екатерина Ивановна Трубникова - доктор экономических наук, доцент, Департамент менеджмента, Санкт-Петербургская школа экономики и менеджмента, Национальный исследовательский университет «Высшая школа экономики». Адрес: 194100, Санкт-Петербург, ул. Кантемировская, д. 3. E-mail: ei.trubnikova@gmail.com; etrubnikova@hse.ru
\end{abstract}

Цитирование: Трубникова Е.И. (2020) Проект 5-100: взгляд через призму теории институциональной коррупции // Мир России. Т. 29. № 2. С. 72-91. DOI: $10.17323 / 1811-038 X-2020-29-2-72-91$

Существвут принциииально разнье позищии относительно оценки результатов и текущего состояния Проекта 5-100. С одной стороны, отдельные участники проекта значительно улучшили свои показатели, и анализ официального ресурса, посвященного Проекту 5-100, даже позволяет сделать оптимистичные выводы об успехе в его реализации. С другой стороны, ни один из университетов не приблизился к желаемой позиции, а именно к вхождению в 100 лучших университетов мира в глобальных международных рейтингах. Более того, отдельнье участники проекта до сих пор вообще не смогли войти ни в глобальнье, ни даже в предметные рейтинги. В статье анализируются причинь неудач вузов проекта, в первую очередь его аутсайдеров, акиентируется внимание на наличии спроса на неэффективные институты внутри университетской средь. Для объяснения причин неудач российских университетов используется теория институцииональной коррупции. Имитация расходов на науку создает иллюзию о возможности достижения выбранными для участия в проекте вузами желаемых ориентиров, а единичные «истории успеха» в российской академической среде легитимируют недобросовестнье действия других акторов. Многие затраты, понесенные участниками, несмотря на то, что не противоречат нормативным положениям, в действительности не соответствуют индикаторам развития университетов, заявленным в дорожных картах, и программным установкам проекта, а также тем ориентирам, достижения которых общество вправе ожидать от столь крупномасштабных финансовых вливаний. Институционализация хищнических практик может обеспечить выживаемость вуза в краткосрочной перспективе, но не способствует достижению общественно значимых целей. 
Ключевые слова: высшее образование, Проект 5-100, международные рейтинги университетов, институциональная коррупция, игра с системой, хищнические журналы

\section{Введение}

Одной из самых значительных программ, которые реализуются в российской системе высшего образования, является проект повышения конкурентоспособности Проект 5-100른 целью которого стала «максимизация конкурентной позиции группы ведущих российских университетов на глобальном рынке», а именно вхождение к 2020 г. не менее 5 российских университетов в первые 100 лучших университетов в международных рейтингах (QS, ARWU и THE). В настоящее время проект охватывает 21 университет, а объем финансирования зависит от группы, в которую попал вуз: в 2019 г. в 1-й группе оказались МФТИ, НГУ, МИСиС, НИУ ВШЭ, МИФИ, ТГУ, ИТМО, во 2-ю вошли КФУ, РУДН, Сеченовский Университет, СПбПУ, ТПУ, ТюмГУ, УрФУ; университеты 3-й группы - БФУ им. Канта, ДВФУ, Самарский университет, СПбГЭТУ «ЛЭТИ», СФУ, Университет Лобачевского, ЮУрГУ.

Несмотря на то, что согласно официальной позиции «для участия в проекте были отобраны сильные университеты, которые имели потенциальные возможности достижения целей и задач проекта» [Ключарев, Неверов 2018, с. 107], уже сейчас очевидно, что шансы на то, что в обозначенные сроки в 100 лучших университетов мира в глобальных рейтингах попадет хотя бы один участник проекта, ничтожно малы. Два из финансируемых по проекту университетов не вошли ни в один из трех глобальных рейтингов: это представитель второй группы - ТюмГУ и представитель третьей группы - БФУ им. Канта. На момент подготовки окончательной версии статьи был опубликован рейтинги QS и THE 2020 г., а также рейтинг ARWU 2019 г.: в 100 лучших университетов мира не вошел ни один участник Проекта 5-100.

При этом анализ официального ресурса, посвященного проекту, позволяет сделать оптимистичные выводы об успехе в его реализации. Как отмечает А. Осипиан, «россияне не разочарованы своей неудачей, <..> они гордятся своими результатами» [Osipian 2018]. Более того, официальный отчет «Проект 5-100 наращивает присутствие в рейтинге мировых университетов ТНЕ» на английском языке имеет наименование "The Times Higher Education World University Rankings: Russia's Success Story” («Всемирный рейтинг университетов The Times Higher Education: история успеха России») и констатирует успехи российских вузов ${ }^{2}$.

Уловкой, которая защищает первоначальную идею о возможности в условиях рентоориентированной экономики добиться международного успеха путем усиленного точечного финансирования, стало смещение фокуса с глобальных рейтингов на подрейтинги. При этом следует отметить, что в Положение о Совете по повышению конкурентоспособности ведущих университетов РФ среди ведущих мировых научно-образовательных центров (ППРФ от 16 марта 2013 г.

\footnotetext{
https://www.5top100.ru/news/112180/

2 The Times Higher Education World University Rankings: Russia's Success Story (2018) // Project, September 26, $2018 / / \mathrm{https}: / / w w w .5 t o p 100 . r u / e n / n e w s / 87872 /$
} 
N 211 ) терминология «предметные рейтинги» попала лишь в 2016 г. (ППРФ от 9 апреля 2016 г. N 287), когда стало очевидным, что первоначальные цели достичь не удается. Таким образом, с точки зрения глобальных рейтингов существующее положение не позволяет оценивать результаты в целом как успех - скорее, как его отсутствие. Определенные достижения есть, если не учитывать общее увеличение рейтингуемых позиций, и если не принимать в расчет, что это рейтинги не глобальные, а предметные и территориальные, и если не обращать внимание на игру с системой, которую используют ее участники. В статье будет представлен анализ текущих результатов участников проекта с фокусом на возможные причины провала, в первую очередь аутсайдеров проекта, в достижении желаемых индикаторов.

Цель представленного исследования заключается в том, чтобы помочь понять причины неудач тех университетов, которые, несмотря на высокие объемы финансирования, так и не смогли повторить успехи своих конкурентов и партнеров, а также в том, чтобы дополнить существующий анализ эмпирическими наблюдениями исследователя внутри этой системы. Для достижения обозначенной цели использована теория институциональной коррупции. В исследовании использовались официальные документы, научные публикации, публикации в средствах массовой информации, интервью с представителями университетов, а также опыт автора, полученный в период работы в принципиально разных вузах, участвующих в Проекте 5-100. Большое внимание было также уделено закупкам, осуществляемым российскими вузами, которые представлены на портале Единой информационной системы в сфере закупок.

\section{Дискуссия о готовности российских университетов к международной конкуренции: институциональные ловушки российской академической среды}

При анализе результатов Проекта 5-100 исследователи отмечают определенные плюсы его реализации: рост публикационной активности, интернационализация, выход вузов на иной уровень развития, появление новых инициативных проектов и др. [Польдин, Матвеева, Стерлигов, Юдкевич 2017; Turko, Bakhturin, Bagan, Poloskov, Gudym 2016; Гельман (1) 2018; Гельман (2) 2018 и др.]. Однако не все согласны с его исключительно положительной оценкой [Зборовский, Амбарова 2019; Osipian 2018; Balzer 2018 и др.]: так, уже в первые годы проекта высказывались мнения о неготовности институциональной системы российского высшего образования к международной конкуренции как среди вузов-участников, так и за пределами проекта [Шереги, Арефьева 2014]3. Среди рисков экспертами отмечались не только общая неподготовленность университетов к значительным преобразованиям, но и риск субъективизма и неэффективного использования ресурсов в ходе его реализации.

\footnotetext{
3 Взаимодействие вузов-участников Проекта 5-100: конкуренция или интеграция? (2014) // Окна академического роста. 3 февраля 2014 // https://okna.hse.ru/news/134100034.html; Дорога в топ-100: «дорожные карты» исследовательских университетов (2014) // Окна академического роста. 13 марта 2014 // https://okna.hse.ru/news/134102325.html; По дороге в топ-100 (2013) // Окна академического роста. 3 октября 2013 // https:/okna.hse.ru/news/133578827.html. См. также п. 8 раздела 3 Стратегии Новосибирского государственного университета экономики и управления «НИНХ» до 2025 г. // https://nsuem.ru/university/facts-and-figures/strategy/
} 
Следует отметить, что еще до реализации проекта в отдельных исследованиях отмечалась неспособность отечественных университетов «достичь расчетного уровня эффективности при наличных ресурсах» с акцентом на существующую систему стимулов с ориентацией «на захват ренты» [Олейник 2011, с. 68]. В этом плане ситуация с Проектом 5-100 не многим отличается от иных национальных проектов, неудачи которых аналитики видят в несоответствии реальных и заявляемых задач их создания, в отсутствии спроса на результат: так, среди проблем реализации отмечается приоритет освоения бюджетных средств над результатом (см. напр., [Иноземцев 2019]); пиар и демонстрация «частичных и временных» успехов [Гельман (1) 2018], банальное «проедание» ресурсов, предназначенных для развития [Соколов 2012], а также восприятие проекта многими участниками в качестве эпизодического подарка, за который надо лишь «правильно отчитаться» [Гельман (1) 2018]. Как результат - отдельные вузы проекта попали в ловушку достижения формальных показателей, субъективизма и неэффективного использования ресурсов.

Одновременно с вышесказанным иерархическая сегрегация и удержание «части вузов на более низких уровнях бюджетного и прочего обеспечения» [Сенашенко 2017, с. 11; Урбан 2019, с. 126] приводят к неравномерному распределению абитуриентов между учебными заведениями. Поддерживаемые государством университеты для создания репутации в рамках международных рейтингов активно финансируют пиар-кампании в СМИ. Как следствие, в информационном домене почти полностью отсутствует критика отдельных участников проекта с крайне низкими результатами, как, впрочем, сложно найти и критику проекта в целом.

В представленном исследовании особое внимание уделяется влиянию проблемы институциональной коррупции на развитие образовательной и научной сферы в целом и на реализацию Проекта 5-100 в частности. В отличие от обычной коррупции, теория институциональной коррупции рассматривает в качестве главной проблемы не столько персональное нечистоплотное поведение должностных лиц, сколько некорректный дизайн системы, который вынуждает участников принимать решения, противоречащие общественным интересам [Thompson 1995; Lessig 2013; Trubnikova, Trubnikov 2018]. Само понятие «институциональная коррупция» появилось в середине 1990-х гг. [Thompson 1995], и в последнее десятилетие эта концепция активно популяризируется профессором Гарвардского университета Лоуренсом Лессигом, утверждающим, что сама система стимулов и влияния в значительной степени определяет результат функционирования, который может быть очень далеким от первоначальных общественно значимых целей [Lessig 2013]. Важной особенностью институциональной коррупции является то, что решения, которые прямо противоречат реальным общественным интересам, могут и не выходить за пределы правого поля.

\section{Целевые установки Проекта 5-100 и особенности международных рейтингов: честные результаты и игра с системой}

У каждого из востребованных в рамках Проекта 5-100 рейтингов есть свои особенности, отдельные моменты которых критикуются научным сообществом (см., напр., [Bookstein, Seidler, Fieder, Winckler 2010; Holmes 2006]). Анализ 
доминирующих индикаторов рейтингов формирует представление, что наиболее просто могут быть достигнуты индикаторы репутации, составляемые по результатам опросов, индикаторы соотношения студентов и преподавателей и доля иностранных студентов и преподавателей. Именно поэтому на рейтинге $\mathrm{QS}^{4}$, где открытые для игры с системой индикаторы имеют доминирующее значение, были сфокусированы усилия большинства российских вузов. Анализ качественного состава общего рейтинга QS показывает, что у большинства вузов Проекта 5-100, представленных в рейтинге, позиция в QS связана в большей степени с показателем соотношения студентов и преподавателей, а также с данными, характеризующими доли иностранных студентов и преподавателей.

Труднее всего добиться достижения индикаторов продуктивности исследовательской деятельности, и, видимо, именно с этим связан тот факт, что в рейтинге $\mathrm{ARWU}$, который, в первую очередь, уделяет внимание этим аспектам, присутствует наименьшее количество российских вузов из всех трех рейтингов 11 вузов, в том числе только 9 участников Проекта 5-100. Анализ дорожных карт вузов-участников проекта показывает, что отдельные высшие учебные заведения даже не включили данный рейтинг в свою дорожную карту. Для подтверждения слабой представленности российских университетов в ведущих мировых научных журналах можно привести данные рейтинга Лейденского университета, который при сравнении учебных заведений учитывает лишь один индикатор - наукометрию - и основан исключительно на библиографических данных из базы данных Web of Science Clarivate Analytics ${ }^{6}$. В этом рейтинге в 1000 лучших университетов планеты входят лишь 3 российских университета - МГУ (266 место), СПбГУ (515 место) и участвующий в Проекте 5-100 НГУ (937 место).

Рейтинг $\mathrm{THE}^{7}$ изначально не рассматривался многими участниками проекта в качестве главного целевого ориентира, но позднее стало понятно, что попадание в него возможно через массовую покупку научных публикаций (ниже будет уделено внимание данной возможности игры с системой), и, видимо, этот факт объясняет, что со временем именно в этом рейтинге сконцентрировалось наибольшее число российских вузов, причем не только участников Проекта 5-100.

Ниже представлен краткий анализ общих результатов вузов Проекта 5-100 в международных рейтингах. В рамках исследования рассмотрены только глобальные рейтинги QS, ARWU и THE; оценка региональных и предметных рейтингов в цели данной работы не входит. Следует отметить, что во время реализации проекта в анализируемых рейтингах количество вузов изменилось: так, рейтинг ТНЕ в 2015 г. включал лишь 400, в 2016 г. - 800, а в 2019 г. - 1258 вузов (в 2015 г. изменился источник библиометрических данных, используемых при его составлении ${ }^{8}$. В ARWU в 2016 г. было представлено только 500 университетов, в 2017 г. - 800, а в 2018 г. - 1000. Рейтинг QS в 2014 г. включал немногим

\footnotetext{
4 QS World University Rankings // https://www.topuniversities.com/

5 Academic Ranking of World Universities // http://www.shanghairanking.com/

6 CWTS Leiden Ranking 2018 // http://www.leidenranking.com

7 Times Higher Education // https://www.timeshighereducation.com/

8 Times Higher Education Announces Reforms to its World University Rankings (2014) // Times Higher Education, November 19, 2014 // https://www.timeshighereducation.com/world-university-rankings/news/times-higher-educationannounces-reforms-to-world-university-rankings
} 
более 800 вузов, в 2019 г. - более 1000. Поэтому важно понимать, что попадание многих российских университетов в данные рейтинги связано, в том числе, и с изменениями самих рейтингов, на что указывают и представители рейтингующих организаций 9 .

\section{Участники Проекта 5-100 в рейтинге QS}

Глобальный рейтинг QS 2019 г. включал 27 российских вузов, в том числе 17 из 21 участника проекта (4 вуза Проекта 5-100 - Сеченовский Университет, ТюмГУ, БФУ им. Канта и СПбГЭТУ «ЛЭТИ»- в рейтинг не попали). Ни один из университетов проекта не смог войти в топ-200, и лишь 2 университета (НГУ и ТГУ) входят в топ-300. Несмотря на то, что большинство участников проекта смогли войти в глобальный рейтинг QS, только у отдельных вузов за последние годы наблюдаются значительные положительные изменения: практически все вузы 1-й группы показали рост; среди университетов 2-й группы только у одного (ТПУ) произошло значительное улучшение позиции; позитивная динамика была продемонстрирована также КФУ. Позиции же большинства участников 2-й и всех университетов 3-й группы не постоянны и колеблются то в одну, то в другую сторону. В рейтинге QS-2020 г. среди 1000 вузов индексируются лишь 25 российских университетов (то есть 2 вуза лишились своих мест в числе рейтингуемых, в том числе один участник Проекта 5-100).

\section{Участники Проекта 5-100 в рейтинге $A R W U$}

Анализ рейтинга ARWU, с одной стороны, может привести к иллюзорным выводам о достижении определенных результатов отдельными вузами проекта (если, конечно, не брать в расчет увеличение общего количества представленных в рейтинге университетов в два раза), с другой стороны, более половины участников проекта так и не смогли попасть в него: в рейтинге до 2018 г. присутствовали только 2 российских университета проекта (МФТИ - позиция 501+; НГУ - позиция 401+), но уже в 2018 г. (когда число вузов в рейтинге возросло до 1000) картина значительно поменялась: количество участников Проекта 5-100 возросло до десяти. При этом их позиции нельзя назвать высокими: лишь 2 участника вошли в топ-500 (прежнее число университетов в рейтинге) - это присутствующие в рейтинге ранее МФТИ и НГУ. За бортом остались МИФИ, РУДН, Сеченовский Университет, ТюмГУ и все университеты 3-й группы. Уже годом позже число участников проекта сократилось до 9: вошел МИФИ, но своих позиций лишились 2 вуза 2-й группы (СПбПУ и ТПУ). В топ-500 также входят исключительно те же 2 университета-участника проекта.

\footnotetext{
9 Представитель Times Higher Education: БФУ им. И. Канта претендует войти в престижный международный рейтинг университетов THE WUR // БФУ им. Канта // https://old.kantiana.ru/analytics/255077/
} 
Участники Проекта 5-100 в рейтинге ТНЕ

По итогам рейтинга 2020 г. все участники смогли попасть в глобальный рейтинг ТНЕ (за исключением 2 вузов - ТюмГУ и БФУ им. Канта), однако обращают на себя внимание множественные примеры отрицательной динамики, что входит в прямое противоречие с какими-либо заявлениями об успехе: позиции значительной части университетов в данном рейтинге лишь ухудшились, при этом в ряде случаев имеет место падение более чем на 200, 300 и более позиций. Только 3 университета действительно улучшили свои результаты: МФТИ, НИУ ВШЭ, ТГУ.

\section{Направления развития дорожных карт университетов Проекта 5-100}

Одним из предполагаемых условий для получения финансовой поддержки участниками проекта является выполнение утвержденных планов (дорожных карт), в которых отражены основные мероприятия по повышению конкурентоспособности вуза и которые включают достаточно большой набор индикаторов, корреляция которых с целевыми установками Проекта 5-100 прослеживается не всегда. Формулировки показателей дорожных карт разных вузов проекта также различаются, однако имеются общие направления развития, которые можно объединить в несколько групп: «образование», «наука» и «кадры» [Шереги, Арефьева 2014]. В действительности, многие индикаторы либо перекликаются, либо взаимосвязаны, но это непринципиально для целей данной статьи. Очевидно, что усилия и расходы вузов должны соответствовать целевым установкам проекта, одним из наиболее значимых требований которого является вхождение университета в топовые разделы мировых рейтингов. Ниже представлен анализ направлений дорожных карт с акцентом на выявлении институтов влияния, подрывающих возможности системы достичь общественно значимые ориентиры.

\section{Образование}

В рамках направления «образование» в дорожных картах участников предусмотрены показатели, повышающие привлекательность вуза для студентов, и фигурируют такие мероприятия, как «привлечение зарубежных студентов для обучения в российских вузах», «реализация партнерских образовательных программ с иностранными университетами и ассоциациями университетов», «улучшение позиций университета в международных рейтингах посредством сети Интернет», «формирование бренда университета на внешних рынках» и т.д.

Для повышения привлекательности отдельные участники программы направляют ресурсы непосредственно на пиар-кампании в СМИ, в т.ч. на создание имиджа 
вуза, популяризацию научных достижений сотрудников ${ }^{10}$, а также на услуги по привлечению иностранных граждан для обучения в вузе ${ }^{11}$. При этом доходы информационных площадок начинают зависеть от содержания информационного контента, и, как следствие, в информационном домене отсутствует критика отдельных участников проекта с крайне низкими результатами. Это дает возможность формировать необходимые потоки абитуриентов при сохранении низких реальных показателей научной и образовательной деятельности. В итоге информация в СМИ создает ложную репутацию учебному заведению, привлекая в его стены талантливых абитуриентов с высокими баллами ЕГЭ, которые при отсутствии такой информационной асимметрии могли бы выбрать другие вузы. Расходуя выделенные средства на пиар-кампании и в отдельных случаях создавая значимые, но при этом ложные сигналы на рынке, вузы отвлекают абитуриентов в первую очередь не от зарубежных университетов, а от иных российских вузов, не обладающих ресурсами на проведение рекламных кампаний. Так, согласно опросу бакалавров выпускного года обучения одного из аутсайдеров Проекта 5-100, проведенному автором данной статьи, 83\% студентов одной из специальностей вуза при ответе на утверждение «Если я решу продолжить обучение в магистратуре, то я обязательно сделаю это в этом же университете» выбрали вариант ответа «категорически не согласен», оставшиеся 17\% выбрали опцию «не согласен» ${ }^{12}$. Но как это ни парадоксально звучит, вуз не заинтересован в формировании репутации среди студентов, поскольку дорожная карта в качестве ориентира включает увеличение доли магистрантов из других вузов, которых можно привлекать ложными сигналами, создаваемыми за счет средств проекта.

В случае с российскими вузами рост показателя количества иностранных студентов может быть достигнут за счет студентов из бывших республик СССР и стран третьего мира ${ }^{13}$. Более того, вузы активно тратят денежные средства на мероприятия по привлечению иностранных студентов. При этом в отдельных случаях иностранные студенты проходят ступени от бакалавриата до аспирантуры без особых усилий, а вузы закрывают глаза на низкие результаты обучения ввиду очевидной значимости показателя количества студентов-иностранцев. В практике респондентов из вузов проекта встречались студенты и даже аспиранты-выпускники, не владеющие ни русским, ни английским языком (процесс общения аспиранта и руководителя осуществлялся посредством Google-переводчика).

В этом смысле российские вузы, действительно, становятся конкурентоспособными на мировой арене, но в чем тогда состоит польза для российской системы образования? Контролирующие органы довольны, так как это коррелирует с индикаторами отдельных международных рейтингов, хотя в реальности это всего лишь имитация развития международной активности вуза. И, несмотря на то, что Россия входит в десятку стран с наиболее высоким показателем

\footnotetext{
10 См. закупки № 31908170078; № 31705507482; № 31907824050; № 31806397808; № 31603338878; № 31806370208; № 0369100017616000346; № 0369100017616000344. Здесь и далее представлены номера закупок, осуществляемых российскими университетами через Единую информационную систему в сфере закупок // http://zakupki.gov.ru

11 Закупки № 31806238220 ; № 31806351384 .

12 Аналогичный опрос бакалавров другой специальности показал, что 7\% респондентов допускают мысль о поступлении в магистратуру в своем вузе.

13 Закупка № 31603609893.
} 
количества иностранных студентов, отечественные вузы практически не представлены в международных совместных программах [Абанкина и др. 2018, с. 58]. Некоторые исследователи ставят под сомнение возможности использования данного индикатора для оценки университетов, справедливо отмечая, что «число преподавателей из Ботсваны» и «число студентов из Чили» не могут оказывать влияния на качество и уровень вуза [Blanchflower 2011]. Однако в рамках системы, требующей определенного индикатора, университеты предпринимают различные действия и расходуют средства на увеличение данного показателя, изымая финансы из полезных видов активности.

\section{Наука}

В ходе реализации в дорожных картах направления «наука» определены мероприятия, способствующие повышению уровня научных исследований и направленные на «привлечение, развитие и академическую мобильность кадров», «создание научных коллективов», «привлечение молодых сотрудников с опытом работы в научно-исследовательской и образовательной сферах в ведущих иностранных и российских университетах и научных организациях» и другие.

Следует отметить, что исследовательская активность в вузах может поощряться как посредством различных систем предоставления грантов, так и через стимулирующие положения. Поскольку повышение публикационной активности отвечает целям Проекта 5-100, вузы самостоятельно определяют механизмы и инструменты поощрения активности своих сотрудников и выбирают те направления, которые являются для них приоритетными. Так, вуз может предусматривать стимулирование публикационной активности по близкой руководству тематике ${ }^{14}$, что может объясняться стремлением получения дополнительной ренты определенным кругом лиц, которая будет сигнализировать о занимаемом в организации положении, что способствует выделению в рамках организации групп доминирования.

Если говорить об игре с системой в случае публикационной активности, то реальной проблемой становятся хищнические журналы, реализующие недобросовестную модель научной издательской деятельности и публикующие статьи за плату без проведения процедур рецензирования, что неоднократно было отмечено исследователями (см. напр., [Sterligov, Savina 2016; Трубникова 2017; Sterligov 2018; Matveeva, Sterligov, Yudkevich 2019]). Подобные издания пользуются огромной популярностью у многих участников проекта: так, анализ сайта государственных закупок позволяет выявить множество объявлений о закупках, произведенных российскими университетами, по финансированию публикаций. Следует иметь в виду, что такой подход демонстрирует лишь вершину айсберга и не позволяет увидеть всю картину (закупки на сумму, не превышающую установленных требований для обязательного проведения через систему госзакупок, а также публикации, оплаченные лично авторами). Перечень лотов сайта госза-

\footnotetext{
14 Например, стимулирующее положение БФУ им. Канта предусматривает премирование статей в рамках предметных категорий Demography; Geography, Planing and Development; Philosophy с надбавкой в 50\% к базовой премии // https://www.kantiana.ru/upload/iblock/3c9/2019_POLOZHENIE-o-vyplatakh-za-publikatsii.pdf.
} 
купок на данную тематику весьма разнообразен ${ }^{15}$, в том числе распространены закупки по схеме с единственным поставщиком, а также проведение закупок через фирмы-посредники. Среди объявлений есть как лоты от активно финансируемых университетов (участников Проекта 5-100, федеральных университетов, опорных университетов и др.), так и лоты от иных вузов. Особого внимания заслуживают оптовые закупки: например, закупка участника Проекта 5-100 КФУ на сумму 35 тыс. долларов ${ }^{16}$, где в качестве лота указана публикация статей в издательстве, которое в 2010 г. было включено в лист predatory open access publishers (список Джеффри Билла ${ }^{17}$ ), а позднее отнесено к так называемым пограничным случаям [Butler 2013]. Также интересны лоты по созданию рубрик и оптовой оплате публикаций в журналах, которые имеют положительную репутацию, не включены в черные списки и официально заявляют, что публикации в них бесплатны ${ }^{18}$.

Следует отметить, что отдельные вузы проекта пытаются бороться с этой практикой и предъявляют высокие требования к публикационной активности сотрудников, однако подобные требования может выдвигать лишь университет, уже обладающий исследовательской командой. Введение же аналогичных требований в региональных высших учебных заведениях, в том числе вузах-участниках проекта, приведет к отказу со стороны руководства от продления контрактов со значительной частью сотрудников организаций. Если применить, например, требования по занятию позиции одного из лидеров Проекта 5-100 к его аутсайдерам, то значительное количество заведующих кафедрами, директоров институтов, профессоров, доцентов (как, впрочем, и представителей ректорского состава), в лучшем случае, сможет пройти лишь на должность преподавателя или ассистента ${ }^{19}$. Тем не менее подобные критерии могли бы стать ориентиром для региональных вузов, однако этого не происходит, потому что это не отвечает интересам основных стейкхолдеров, которые определяют развитие этих организаций.

В то же время хищническая модель поведения журналов может давать свои результаты. Многие издания, которые вошли в список Дж. Билла и позже исключены из Scopus, в период индексации находились в первом и втором квартилях. Недобросовестное поведение университетов также может приносить плоды: например, для включения в рейтинг ТНЕ вузу необходимо преодолеть пороговые значения (более 1000 статей за 5 лет при выполнении ежегодного минимума не менее 150 публикаций). Вышеупомянутый анализ закупок российских университетов

15 Закупки № 31907933112; № 31705655759; № 31503086925; № 31907665460; № 31907601135; № 31807298671; № 31807277499 ; № 31705836473 ; № 31806497740 ; № 31806341349 ; № 31907901655 .

16 Закупка № 31806408193.

17 В так называемые списки predatory publishers (хищнические издания) включены академические издания, которые реализуют, по мнению составителей, недобросовестную модель научной издательской деятельности. Такие издания, как правило, взимают плату с авторов манускриптов и не предоставляют услуги научного рецензирования в достаточном объеме. Дж. Билл явился автором первой наиболее известной попытки создания такого списка [Beall 2012]. В настоящее время многие университеты ориентируются на список Дж. Билла

18 Закупки № 31807155824 ; № 31705865519.

19 Так, например, в соответствием с Критериями соответствия претендентов должности ППС НИУ ВШЭ (https:/pps.hse.ru/1st2020/criteria/) даже для занятия должности старшего преподавателя требуется не менее 2 публикаций за последние 3 года, в том числе не менее 1 публикации в изданиях, индексированных в $W o S$ или Scopus (https://www.hse.ru/science/our/evaluation). При этом у университета существует перечень изданий (так называемый черный список), публикации в которых не учитываются при оценке публикационной активности сотрудников. 
позволяет сделать вывод, что у отдельных университетов есть стойкое убеждение, что рейтинг можно «купить» вместо того, чтобы мотивировать исследователей и развивать собственные научные направления.

Более того, данная практика распространяется (и институализируется) и за пределами проекта, в результате вузы, не попавшие в ту или иную программу финансирования, копируют приемы финансируемых конкурентов. Цель такого рода активности очевидна - нарастить публикационные результаты для доступа к ресурсам (для участия в финансируемых государственных проектах, получения грантовой поддержки и прочее). С одной стороны, институционализация этих действий может обеспечить выживаемость вуза в краткосрочной перспективе, но ни в коей мере не способствует достижению общественно значимых целей. С другой стороны, вузы проекта, использующие такую модель, продолжают получать ресурсы и преференции, что дает основание делать удручающие выводы о ее эффективности.

Не лучшая ситуация сложилась и в сфере грантовой поддержки научных исследований, когда внешние гранты могут «закрываться» недобросовестными публикациями, а внутренние - распределяться среди «своих» по итогам «закрытого конкурса», результатом которого может стать финансирование коллектива под руководством сотрудника, не имеющего собственных публикаций. Для легитимации выделения ресурсов для «своих» нередко привлекаются известные сторонние исследователи в рамках синхронной мобильности, при этом вакансии сотрудников открываются по «нужным» тематикам со специфическими характеристиками, которые однозначно определяют победителя конкурса и т.д. И, как справедливо отмечается в исследовании, посвященном особенностям академического рынка труда, «связи заменяют собой рыночные механизмы» [Финкельштейн, Иглесиас, Панова, Юдкевич 2014, с. 34], что способствует укреплению структуры институциональной коррупции.

Еще одним инструментом в рамках развития научного направления выступает институт «ведущего мирового ученого» (ВМУ), который предполагает привлечение руководством вуза известных ученых для формирования научных школ, подготовки исследователей и иных видов активности на своей территории. И благая, на первый взгляд, цель в отдельных недобросовестных университетах проекта обретает совершенно иные формы. В качестве ВМУ зачастую приглашаются знакомые администрации вуза ученые без проведения реальных и публичных конкурсных процедур. Согласно анализу официальных ресурсов участников проекта, вузы иногда вообще не афишируют имена тех специалистов, которые были привлечены за счет средств проекта на позиции ВМУ. Такой специалист просто выступает инструментом легитимизации освоения средств проекта; имеют место случаи, когда привлекаемый на позицию ВМУ сотрудник обладает лишь российской степенью кандидата наук (или вообще имеет только степень магистра ${ }^{20}$ ) и получает солидное вознаграждение за несколько посещений вуза в год, в течение которых, в том

\footnotetext{
20 Например, для легитимации привлечения под категорию ВМУ лица, имеющего лишь степень магистра, в БФУ им. И. Канта в «Положение по приглашению ВМУ» наряду с должностями «профессор», «профессор (исследователь)», «профессор (консультант)» была введена специальная позиция «преподаватель» // https:/old.kantiana.ru/students/grants/Положение\%20о\%20порядке\%20отбора\%20для\%20приглашения\%20и\%20 приема\%20на\%20работу\%20ведущих\%20мировых\%20ученых.pdf
} 
числе, проводит семинары в частной бизнес-школе, принадлежащей инициировавшему его приглашение директору института ${ }^{21}$.

Особо следует остановиться на таком инструменте, как академическая мобильность. Среди мероприятий, финансируемых из Проекта 5-100, можно найти и конкурсы, проводимые прикладными университетами, и сомнительные с академической точки зрения соревнования, организованные в туристически привлекательных местах, и даже курсы английского языка на Мальте 22 . По факту многие активно посещаемые российскими научными сотрудниками события имеют своей реальной целью туризм: тур оплачивается из бюджета организации, создает иллюзию академической мобильности, при этом уровень мероприятия, как и его организатор, перестают иметь какое-либо серьезное значение. В данном случае такие расходы становятся причиной возникновения дефицита средств на реальную научную деятельность и, как итог, отсутствия университета, проявляющего особую расточительность подобного характера, не только в глобальных, но и в предметных рейтингах. Но, как отметил респондент-руководитель среднего звена одного из аутсайдеров проекта, «... ну и что, что нет научных результатов, зато студенты и преподаватели Россию и мир посмотрели».

\section{Kadpbl}

В рамках направления «кадры» в дорожных картах участников Проекта 5-100 заявлены процедуры, направленные на «формирование эффективной системы управления вузом», «формирование кадрового резерва руководящего состава вуза», «привлечение на руководящие должности специалистов с опытом работы в ведущих иностранных и российских университетах и научных организациях» и другие.

В целях проводимого исследования интересными выглядят конкурсные процедуры. Во многих анализируемых случаях выявляются не только факты институциональной коррупции, когда действия игроков, несмотря на их явный диссонанс с общественными целями и интересами, находятся в правовом поле, но также не выходящий за рамки правовых норм фаворитизм, когда преференции отдаются

\footnotetext{
21 См. информацию на сайте одной из частных калининградских организаций, активной на рынке бизнес-образования. Перманентная ссылка на версию сайта kibs.ru от 14.08.2019, организованная с использованием сервиса Harvard Library Innovation Lab, — https://perma.cc/5SS8-3MXG (Дата обращения 22.12.2019).

22 Делегация БФУ им. И. Канта принимала участие в международной стратегической маркетинговой симуляции Зимний Маркстрат (2019) // БФУ им. И. Канта. 12 февраля 2019// https://kantiana.ru/news/proekt-5-100/delegatsiyabfu-im-i-kanta-prinimala-uchastie-v-mezhdunarodnoy-strategicheskoy-marketingovoy-simulya/?bxajaxid=70d9374ed6 ae1f0da085f46d30f8dc76; Европейская академия инноваций включила в ТОП-10 два стартапа с участием магистрантов БФУ им. Канта (2017) // БФУ им. И. Канта. 3 августа 2017 // https://www.kantiana.ru/news/universitet/ evropeyskaya-akademiya-innovatsiy-vklyuchila-v-top-10-dva-startapa-s-uchastiem-magistrantov-bfu-im-k/?bxajaxid=5 111c2a93592bc45f58241669bb0acb4; Студент БФУ им. И. Канта принял участие в курсах по изучению иностранного языка на базе языкового центра Гейдельберга (2019) // БФУ им. И. Канта. 15 января 2019 // https://www.kantiana. ru/news/universitet/student-bfu-im-i-kanta-prinyal-uchastie-v-kursakh-po-izucheniyu-inostrannogo-yazyka-na-bazeyazykovo/; Студентка института гуманитарных наук БФУ им. И. Канта прошла интенсивные курсы английского языка на Мальте (2018) // БФУ им. И. Канта. 28 декабря 2018 // https://www.kantiana.ru/news/universitet/studentkainstituta-gumanitarnykh-nauk-bfu-im-i-kanta-proshla-intensivnye-kursy-angliyskogo-yazyka-n-1009357408/?bxajaxid= 70d9374ed6ae1f0da085f46d30f8dc76
} 
на основе личных предпочтений. В отдельных университетах наблюдается не только имитация конкурсных процедур, но и полная фиктивность мероприятий подобного рода.

В университетской среде многие кадровые решения (включение в кадровый резерв, продление контракта, назначение на должность и т.д.) принимаются кадровой комиссией. Среди вузов Проекта 5-100 можно найти комиссии, где отсутствуют активные исследователи, однако присутствуют представители административного персонала, а также сотрудники и преподаватели без степени ${ }^{23}$.

Основным требованием, предъявляемым на мировом рынке при получении академической позиции, остается публикационная активность претендента. В условиях «кафкианского мира» ${ }^{24}$ академической среды РФ позиции доцентов, профессоров, заведующих кафедрами, директоров институтов и даже ректорского состава могут занимать лица при полном отсутствии собственных публикаций в серьезных изданиях (или с доминированием оплаченных публикаций, в том числе и в хищнических журналах), с очевидным плагиатом в своих диссертациях. Государственные гранты в этих условиях могут получать коллективы под руководством далеких от науки сотрудников администрации вузов, а награды «за особые научные достижения» - лица, таковыми не обладающие. Более того, оппонируя М.М. Соколову, который утверждает, что «вряд ли есть примеры, чтобы $<\ldots>$ ассистенты работали по более длительным контрактам, чем профессора» [Соколов 2019, с. 45], такая система порождает случаи, когда продолжительность контрактов ассистентов и старших преподавателей (в отсутствии публикаций) дольше, чем срок контрактов профессоров (с публикациями), при этом заработная плата профессора при большей аудиторной нагрузке меньше зарплаты не обладающих научной степенью преподавателей ввиду доступа последних к внутривузовским механизмам материального поощрения.

В данной ситуации основным вариантом продления контракта становится получение голосов членов кадровой комиссии, которая в силу особенностей формирования находится в полной зависимости от вузовского топ-менеджмента. В итоге в вузе доминируют преподаватели без ученой степени и кандидаты наук при полном отсутствии научных и иных достижений, в то время как результативные сотрудники, способные «начать выстраивать сеть инклюзивных институтов» (в терминах [Балацжий, Плискевич 2017, с. 114]), системой выбраковываются. Неограниченные полномочия представителей топ-менеджмента вуза, обладающих возможностью блокировать любую критику в свой адрес, превращаются в тот самый «институциональный изъян», который обрекает «институты на деградацию и цементирование экстрактивности» [Балац̧кий, Плискевич 2017, с. 112].

Включение в кадровый резерв также осуществляется решением кадровой комиссии, в результате чего кадровый резерв в недрах активно играющих с системой университетов становится инструментом получения дополнительных доходов для приближенных к руководству сотрудников при полном отсутствии транспарентности процесса и без проведения полноценных процедур конкурсного отбора. В данную группу может попасть и кандидат наук с низкой публикационной актив-

\footnotetext{
23 Например, кадровая комиссия БФУ им. И. Канта включает в себя главного бухгалтера, секретаря приемной комиссии, заведующего подготовительным отделением и даже старшего преподавателя института физкультуры.

24 Об использовании термина Kafkaesque worlds см. [Halffman, Radder 2015].
} 
ностью, и ассистент вообще без таковой. Дорожная карта проекта подразумевает увеличение числа лиц, включенных в кадровый резерв, что создает основу для увеличения дохода и количества приближенных к руководству сотрудников. Дизайн системы подталкивает субъектов, принимающих решения, к защите своего рентного положения, и, как итог, предпочтение отдается тем претендентам, которые не станут в будущем угрозой существующей системе рентных трансферов внутри организации. Подобные механизмы отрицательной селекции полностью разрушают «положительный морально-психологический эффект» от работы в академической сфере, на который указывают отдельные исследователи [Балацкий (1) 2014; Кузьминов, Юдкевич 2007].

К тому же в России, за редким исключением в столичных регионах, полностью отсутствует адекватно работающий академический рынок труда. Объявления о вакансиях в подавляющем большинстве случаев размешаются под конкретных лиц без ожидания подачи документов от не авторизованных на такие действия соискателей. Как правило, конкурс является не более чем имитацией, и он лишь узаконивает «действия сетевого механизма» [Соколов 2019, с. 60]. Несмотря на высокие ориентиры Проекта 5-100 и декларирование необходимости привлечения специалистов из международных центров, большинство вузов проекта не представлены на международных рекрутинговых академических ресурсах. В данной связи следует упомянуть о повышенных рисках для исследователя на территории развивающихся стран (в том числе в РФ): так, привлеченный исследователь может столкнуться с несоответствием обещаний организации условиям работы и незаинтересованностью вуза в реальном развитии. Но, как заметил один из респондентов-представителей руководства университета, входящего в число аутсайдеров Проект 5-100, «сторонний исследователь должен быть готов к тому, что его обманут, это риски, которые всегда нужно принимать в расчет».

Современный институциональный дизайн приводит не только к расходованию средств на не соответствующие программным установкам цели, он полностью искажает результаты программы финансирования. В ситуации, когда любое решение о расходовании средств трактуется как допустимое, принимаются решения (если опустить домыслы о личной выгоде и корысти), не требующие дополнительных трудовых затрат, и, главное, не формирующие виды активности, которые могут привести к изменению сложившегося статус-кво в организации. Более того, для освоения денежных средств руководителями активно финансируемых организаций рационально принимать любые выгодные им решения (даже те, которые не ведут к росту и развитию), если они не противоречат существующим правовым нормам.

\section{Заключение}

В Проекте 5-100 есть и признанные вузы-лидеры, и вузы-аутсайдеры, при этом последние перенимают инструменты, используемые лидерами. Однако следует учитывать, что одни и те же инструменты в зависимости от институциональной среды реализации работают диаметрально противоположным образом, что отчетливо видно при сравнении университетов-участников проекта. 
В условиях извлечения ренты бюджет организации может выступать «дойной коровой» для близких к распределению финансов лиц, а имитационные мероприятия по движению к международным рейтингам - аргументом для получения бюджетных средств. Более того, участие в Проекте 5-100 известных ученых, их краткосрочные визиты или указание аффилиации при публикации работ, как правило, не приносят активно играющим с системой вузам реальных результатов, а лишь легитимируют существующую схему расходования средств. Создается впечатление, что регулятора вполне устраивает существующая система, не способствующая получению желаемых позиций в международных рейтингах, но прекрасно справляющаяся с задачей освоения средств и имитацией полезной деятельности. Хотя, в действительности, пагубность ситуации заключается не только в захвате процедур распределения бюджета, но и в наличии спроса на неэффективные институты, и как это ни парадоксально, но значительное количество представителей академической среды от этого выигрывает. В иных институциональных условиях многие доценты, профессора, заведующие кафедрами, директора институтов и представители ректората (особенно если говорить об аутсайдерах проекта) не смогли бы занимать свои позиции без публикационной активности должного уровня и ощутимых результатов, тем не менее в нынешней ситуации их позиции отлично защищены «карманными» кадровыми комиссиями от конкуренции со стороны более результативных претендентов.

Необходимо оговориться, что результаты программ академического превосходства в сфере науки и образования воспринимаются по-разному. С одной стороны, можно смотреть на вещи оптимистично (как это делает российский регулятор) и говорить об успехах: безусловно, отдельные вузы-участники Проекта 5-100, сформировавшие реальные, а не фиктивные исследовательские команды, только выиграли от данного проекта. С другой стороны, за громкими лозунгами следует распознать истинное положение дел. И если говорить об успехе проекта, то он, безусловно, есть, но, в первую очередь, у тех, кто получил доступ к ресурсам и их распределению. Также следует перечислить и других бенефициаров: хищнические журналы; организаторы около- и псевдо-научных и образовательных мероприятий; студенты и преподаватели, за государственный счет «посмотревшие мир»; молодые «ученые» и администраторы, без особых трудов и заслуг получающие «погоны» и не соответствующие их уровню зарплаты; отдельные ученые (причем не всегда высокого уровня) и даже приглашенные в качестве ВМУ бизнес-консультанты, которым выплачиваются заоблачные вознаграждения за несколько посещений университета в год, и т.д.

По разным критериям многие вузы-участники стали выглядеть лучше, чем до начала проекта, однако оценка общего результата для системы высшего образования в целом предполагает не только выигрыш бенефициаров, но и проигрыш тех, кто остался «за бортом» Проекта 5-100. Особенно если учитывать, что финансирование участников проекта означает неполучение денежных средств другими вузами. Игнорирование регулирующими структурами факта отсутствия у университета реальных и объективных результатов от участия в программе финансирования, а также крайне неэффективное использование полученных ресурсов усугубляют текущие проблемы. Самым прискорбным в сложившейся ситуации является тот факт, что значительные средства, выделяемые по программе развития, очень часто идут не на реальное развитие академической системы, а оседают в карманах 
неэффективных менеджеров либо вообще просто перенаправляются на не приносящую общественно полезного результата деятельность, которая создает для проверяющих чиновников иллюзию возможности достижения желаемых ориентиров, и более того, сама система, как видно из примера Проекта 5-100, позволяет подстраивать ориентиры под получаемые результаты.

\section{Литература}

Абанкина И.В., Беликов А.А., Гапонова О.С., Дудырев Ф.Ф., Корешникова Ю.Н., Коршунов И.А., Косарецкий С.Г., Мерцалова Т.А., Платонова Д.П., Сорокин П.С., Таловская Б.М., Фрумин И.Д., Нисская А.К. (2018) Глобальная конкурентоспособность российского образования. Материалы для дискуссии. Т. 3. Вып. 20. М.: ВШЭ.

Балацкий Е.В. (1) (2014) Истощение академической ренты // Мир России. Т. 23. № 3. С. 150-174.

Балацкий Е.В. (2) (2014) Оценка академической ренты // Вопросы экономики. № 10. С. 97-113.

Балацкий Е.В., Плискевич Н.М. (2017) Экономический рост в условиях экстрактивных институтов: советский парадокс и современные события // Мир России. Т. 26. № 4. С. 97-117.

Гельман В.Я. (1) (2018) Исключения и правила: «истории успеха» и «недостойное правление» в России (часть 1) // Общественные науки и современность. № 5. С. 48-60.

Гельман В.Я. (2) (2018) Исключения и правила: «истории успеха» и «недостойное правление» в России (часть 2) // Общественные науки и современность. № 6. С. 5-15.

Зборовский Г.Е., Амбарова П.А. (2019) Мечта о хорошем образовании: противоречия развития образовательных общностей в российских университетах // Мир России. Т. 28. № 2. С. 98-124.

Иноземцев В. (2019) Кошелек для бюрократии. Владислав Иноземцев о том, почему российские нацпроекты обогащают чиновников, а не страну // Спектр.Пресс. 18 февраля 2019 // https://spektr.press/koshelek-dlya-byurokratii-vladislav-inozemcev-o-tompochemu-rossijskie-nacproekty-obogaschayut-chinovnikov-a-ne-stranu/

Ключарев Г.А., Неверов А.В. (2018) Проект «5-100»: некоторые промежуточные итоги // Вестник Российского университета дружбы народов. Серия: Социология. Т. 18. № 1. C. $100-116$.

Кузьминов Я., Юдкевич М. (2007) Академическая свобода и стандарты поведения // Вопросы экономики. № 6. С. 80-93.

Олейник А.Н. (2011) Underperformance в теории и университетской практике // Социология науки и технологий. Т. 2. № 3. С. 68-79.

Польдин О.В., Матвеева Н.Н., Стерлигов И.А., Юдкевич М.М. (2017) Публикационная активность вузов: эффект проекта «5-100»// Вопросы образования. № 2. С. 10-35.

Сенашенко В.С. (2017) О реформировании отечественной системы высшего образования: некоторые итоги // Высшее образование в России. № 6. С. 5-15.

Соколов М.M. (2012) Почему российские университеты не станут лидерами мировых рейтингов? // Полит.ру. 18 октября 2012 // http://m.polit.ru/article/2012/10/08/sokolov_anons/

Соколов М.М. (2019) Трансформирующие и селективные системы: исследование по сравнительной социологии академических рынков и карьер // Вопросы образования. № 2. С. 35-77.

Трубникова Е.И. (2017) Асимметрия информации и тенденции рынка научных публикаций // Высшее образование в России. № 3. С. 26-36.

Урбан О.А. (2019) Социальные практики набора в российских вузах // Мир России. Т. 28. № 2. C. 125-147.

Финкельштейн М., Иглесиас К., Панова А.А., Юдкевич М.М. (2014) Перспективы молодых специалистов на академическом рынке труда: глобальное сравнение и оценка // Вопросы образования. № 2. С. 20-43.

Шереги Ф.Э., Арефьев А.Л. (2014) Методические вопросы оценки реализации проекта «5-100» по рейтингам университетов. М.: Социоцентр. 
Balzer H. (2018) Can Russia Catch up/Keep up? Russian Science and Education in Putin's Fourth Term. Paper for Presentation at ASEEES Annual Meeting, Boston.

Beall J. (2012) Predatory Publishers Are Corrupting Open Access // Nature, vol. 489, no 7415, p. 179 // https://www.nature.com/news/predatory-publishers-are-corrupting-open-access-1.11385

Blanchflower D. (2011) The QS World University Rankings Are a Load of Old Baloney // NewStatesman, September 5, 2011 // https:/www.newstatesman.com/blogs/davidblanchflower/2011/09/world-university-faculty

Bookstein F.L., Seidler H., Fieder M., Winckler G. (2010) Too Much Noise in the Times Higher Education Rankings // Scientometrics, vol. 85, no 1, pp. 295-299.

Butler D. (2013) The Dark Side of Publishing // Nature, vol. 495, no 7442, pp. 433-435// https://www.nature.com/news/polopoly_fs/1.12666!/menu/main/topColumns/ topLeftColumn/pdf/495433a.pdf

Halffman W., Radder H. (2015) The Academic Manifesto: From an Occupied to a Public University // Minerva, vol. 53, no 2, pp. 165-187.

Holmes R. (2006) So That's how They Did It // Rankingwatch.blogspot.com, September 5, 2006 // http://rankingwatch.blogspot.com/2006/09/so-thats-how-they-did-it-for-some-time.html

Lessig L. (2013) Foreword: "Institutional Corruption" Defined // The Journal of Law, Medicine \& Ethics, vol. 41, no 3, pp. 553-555.

Matveeva N., Sterligov I., Yudkevich M.M. (2019) The Russian University Excellence Initiative: Is It Really Excellence that Is Promoted? WP BRP 49/EDU/2019.

OsipianA. (2018) Why Putin's 5-100 Project Is Doomed to Fail//University World News, October 5, $2018 / /$ https://www.universityworldnews.com/post.php?story=20181002154128208

Sterligov I. (2018) Russian Federal Universities: A Bibliometric Comparison with 5Top100, C9 and Ivy League // Higher Education in Russia and Beyond, no 1(15), pp. 17-22.

Sterligov I., Savina T. (2016) Riding with the Metric Tide: Predatory Journals in SCOPUS // Higher Education in Russia and Beyond, no 1, pp. 9-12.

Thompson D. (1995) Ethics in Congress: from Individual to Institutional Corruption, Washington: Brookings Institution.

Trubnikova E., Trubnikov D. (2018) The Problem of Institutional Corruption in the System of Higher Education // Higher Education in Russia, vol. 27, no 12, pp. 29-38.

Turko T., Bakhturin G., Bagan V., Poloskov S., Gudym D. (2016) Influence of the Program "5-top 100 " on the Publication Activity of Russian Universities // Scientometrics, vol. 109, no 2, pp. 769-782.

Yudkevich M., Altbach P.G., Rumbley L.E. (eds.) (2015) Young Faculty in the Twenty-first Century: International Perspectives, New York: SUNY Press.

\title{
Project 5-100: A View through the Prism of the Theory of Institutional Corruption
}

\author{
E. TRUBNIKOVA*
}

*Ekaterina Trubnikova - DSc in Economics, Associate Professor, Department of Management, St. Petersburg School of Economics and Management, National Research University Higher School of Economics. Address: 3, Kantemirovskaya St., Saint Petersburg, 194100, Russian Federation.E-mail: ei.trubnikova@gmail.com; etrubnikova@hse.ru

Citation: Trubnikova E. (2020) Project 5-100: A View through the Prism of the Theory of Institutional Corruption. Mir Rossii, vol. 29, no 2, pp. 72-91 (in Russian). DOI: $10.17323 / 1811-038 \mathrm{X}-2020-29-2-72-91$ 


\begin{abstract}
Views on the outcomes of the Russian academic excellence project 5-100 are completely polarized. Some universities have improved their performance. Analyzing data published on the official website of the project reaffirms the optimistic conclusion about its outcomes. On the other hand, none of the universities included in the project has approached the desired positions among the 100 top universities in the world university rankings. Moreover, there are no reasons to believe that the project will reach its goals within the designated period. From this perspective, the project cannot be considered a success. This article discusses the underlying causes of this situation, and the failure of the project's least successful participants and shows the demand for inefficient institutions in the Russian academic environment. The problem is explained through the theory of institutional corruption. While the imitation of useful activity by universities forms an illusion that the system is moving in the right direction, it is clear that there is a huge gap between the expenditure on and the objectives of the project. This situation is caused by the wrong incentives, the excessive power of bureaucrats responsible for the implementation of the project, and the lack of transparency and public accountability of the universities participating in the project. The project's expenses, despite their compliance with the legal frameworks do not, in fact, correspond to the indicators attested in the universities' roadmaps or the public interest. The institutionalization of predatory practices might contribute to university performance in the short run but does not help to achieve socially desirable goals.
\end{abstract}

Key words: higher education, 5-100, university rankings, institutional corruption, gaming the system, predatory journals

\title{
References
}

Abankina I.V., Belikov A.A., Gaponova O.S., Dudyrev F.F., Koreshnikova Yu.N., Korshunov I.A., Kosareckij S.G., Mercalova T.A., Platonova D.P., Sorokin P., Talovskaya B.M., Frumin I.D., Nisskaya A.K. (2018) Global'naya konkurentosposobnost' rossijskogo obrazovaniya. Materialy dlya diskussii [The Global Competitiveness of Russian Education. Discussion Materials], Moscow: HSE.

Balatsky E.V. (1) (2014) Istoshchenie akademicheskoj renty [The Depleting of Academic Rents]. Mir Rossii, vol. 23, no 3, pp. 150-174.

Balatsky E. (2) (2014) Otsenka akademicheskoj renty [The Estimation of Academic Rent]. Voprosy Ekonomiki, no 10, pp. 97-113.

Balatsky E.V., Pliskevich N.M. (2017) Ekonomicheskij rost v usloviyakh ekstraktivnykh institutov: sovetskij paradoks i sovremennye sobytiya [Economic Growth under Extractive Institutions: the Soviet Paradox and Contemporary Events]. Mir Rossii, vol. 26, no 4, pp. 97-117.

Balzer H. (2018) Can Russia Catch up/Keep up? Russian Science and Education in Putin's Fourth Term. Paper for Presentation at ASEEES Annual Meeting, Boston.

Beall J. (2012) Predatory Publishers Are Corrupting Open Access. Nature, vol. 489, no 7415, p. 179. Available at: https://www.nature.com/news/predatory-publishers-are-corruptingopen-access-1.11385, accessed 14.02.2020. 
Blanchflower D. (2011) The QS World University Rankings Are a Load of Old Baloney. NewStatesman, September 5, 2011. Available at: https:/www.newstatesman.com/blogs/ david-blanchflower/2011/09/world-university-faculty, accessed 14.02.2020.

Bookstein F.L., Seidler H., Fieder M., Winckler G. (2010) Too Much Noise in the Times Higher Education Rankings. Scientometrics, vol. 85, no 1, pp. 295-299.

Butler D. (2013) The Dark Side of Publishing. Nature, vol. 495, no 7442, pp. 433-435. Available at: https://www.nature.com/news/polopoly_fs/1.12666!/menu/main/topColumns/topLeft Column/pdf/495433a.pdf, accessed 14.02.2020.

Finkelstein M., Iglesias K., Panova A., Yudkevich M. (2014) Perspektivy molodykh spetsialistov na akademicheskom rynke truda: global'noe sravnenie i otsenka [The Prospects of Young Professionals in the Academic Labor Market: Global Comparison and Assessment]. Voprosy obrazovaniya, no 2, pp. 20-43.

Gel'man V. (1) (2018) Isklyucheniya i pravila: «istorii uspekha» i «nedostojnoe pravlenie» v Rossii (chast' 1) [Exceptions and Rules: "Success Stories" and "Bad Governance" in Russia (Part 1)]. Obshchestvennye nauki i sovremennost', no 5, pp. 48-60.

Gel'man V. (2) (2018) Isklyucheniya i pravila: «istorii uspekha» i «nedostojnoe pravlenie» v Rossii (chast' 2) [Exceptions and Rules: "Success Stories" and "Bad Governance" in Russia (Part 2)]. Obshchestvennye nauki i sovremennost', no 6, pp. 5-15.

Halffman W., Radder H. (2015) The Academic Manifesto: From an Occupied to a Public University. Minerva, vol. 53, no 2, pp. 165-187.

Holmes R. (2006) So That's how They Did It. Rankingwatch.blogspot.com, September 5, 2006. Available at: http://rankingwatch.blogspot.com/2006/09/so-thats-how-they-did-it-forsome-time.html, accessed 14.02.2020.

Inozemtsev V. (2019) Koshelek dlya byurokratii. Vladislav Inozemtsev o tom, pochemu rossijskie natsproekty obogashchayut chinovnikov, a ne stranu [The Wallet for Bureaucracy. Vladislav Inozemtsev on Why Russian National Projects Enrich Bureaucrats], Spektr.Press, February 2, 2019. Available at: https://spektr.press/koshelek-dlya-byurokratii-vladislav-inozemcevo-tom-pochemu-rossijskie-nacproekty-obogaschayut-chinovnikov-a-ne-stranu/, accessed 14.02.2020.

Klyucharev G.A., Neverov A.V. (2018) Proekt" 5-100": nekotorye promezhutochnye itogi. [Project "5-100": Some Interim Results]. RUDN Journal of Sociology, vol. 18, no 1, pp. 100-116.

Kouzminov Y., Yudkevich M. (2007) Akademicheskaya svoboda i standarty povedeniya [Academic Freedom and the Standards of Behavior]. Voprosy Ekonomiki, no 6, pp. 80-93.

Lessig L. (2013) Foreword: "Institutional Corruption" Defined. The Journal of Law, Medicine \& Ethic, vol. 41, no 3, pp. 553-555.

Matveeva N., Sterligov I., Yudkevich M.M. (2019) The Russian University Excellence Initiative: Is It Really Excellence that Is Promoted? WP BRP 49/EDU/2019.

Olejnik A.N. (2011) Underperformance v teorii i universitetskoj praktike [Underperformance in Theory and University Practice]. Sotsiologiya nauki i tekhnologij, vol. 2, no 3, pp. 68-79.

Osipian A. (2018) Why Putin's 5-100 Project Is Doomed to Fail. University World News, October 5, 2018. Available at: https://www.universityworldnews.com/post. php?story $=20181002154128208$, accessed 14.02.2020.

Poldin O., Matveeva N., Sterligov I., Yudkevich M. (2017) Publikatsionnaya aktivnost' vuzov: effekt proekta «5-100» [Publication Activity of Russian Universities: The Effects of Project 5-100]. Voprosy obrazovaniya, no 2, pp. 10-35.

Senashenko V.S. (2017) O reformirovanii otechestvennoj sistemy vysshego obrazovaniya: nekotorye itogi [On the Reforms in the National Higher Education System]. Vysshee obrazovanie v Rossii, no 6, pp. 5-15.

Sheregi F.E., Arefyev A.L. (2014) Metodicheskie voprosy otsenki realizatsii proekta «5100» po rejtingam universitetov [Methodological Issues of Evaluation of Project 5-100 in Accordance to University Rankings], Moscow: Sotsiotsentr.

Sokolov M. (2012) Pochemu rossijskie universitety ne stanut liderami mirovykh reitingov? [Why Will Russian Universities Fail to Become the Leaders of the World Rankings?]. Polit.ru, October 18, 2012. Available at: http://m.polit.ru/article/2012/10/08/sokolov_anons/, accessed 14.02.2020. 
Sokolov M. (2019) Transformiruyushchie i selektivnye sistemy: issledovanie po sravnitel'noj sotsiologii akademicheskikh rynkov i kar'er [Transformative and Selective Systems: A Study in Comparative Sociology of Academic Markets Careers]. Voprosy obrazovaniya, no 2, pp. 35-77.

Sterligov I. (2018) Russian Federal Universities: A Bibliometric Comparison with 5Top100, C9 and Ivy League. Higher Education in Russia and Beyond, no 1(15), pp. 17-22.

Sterligov I., Savina T. (2016) Riding with the Metric Tide: Predatory Journals in SCOPUS. Higher Education in Russia and Beyond, no 1, pp. 9-12.

Thompson D. (1995) Ethics in Congress: From Individual to Institutional Corruption, Washington: Brookings Institution.

Trubnikova E.I. (2017) Asimmetriya informatsii i tendentsii rynka nauchnykh publikatsij [The Information Asymmetry and Tendencies of the Market of Scientific Publications]. Vysshee obrazovanie v Rossii, no 3, pp. 26-36.

Trubnikova E., Trubnikov D. (2018) The Problem of Institutional Corruption in the System of Higher Education. Higher Education in Russia, vol. 27, no 12, pp. 29-38.

Turko T., Bakhturin G., Bagan V., Poloskov S., Gudym D. (2016) Influence of the Program "5-top 100" on the Publication Activity of Russian Universities. Scientometrics. vol. 109, no 2, pp. 769-782.

Urban O. (2019) Sotsial'nye praktiki nabora v rossiǔskikh vuzakh [Social Practices of Maintaining Enrollment at Russian Universities]. Mir Rossii, vol. 28, no 2, pp. 125-147.

Yudkevich M., Altbach P.G., Rumbley L.E. (eds.) (2015) Young Faculty in the Twenty-first Century: International Perspectives, New York: SUNY Press.

Zborovsky G., Ambarova P. (2019) Mechta o khoroshem obrazovanii: protivorechiya razvitiya obrazovatel'nykh obshchnostej v rossijskikh universitetakh [The Dream of Quality Education: Contradictions in the Development of Educational Communities in Russian Universities]. Mir Rossii, vol. 28, no 2, pp. 98-124. 